\begin{tabular}{|c|c|}
\hline \multirow{3}{*}{ 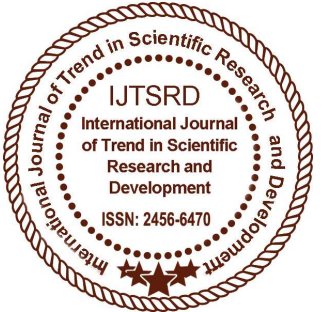 } & $\begin{array}{l}\text { International Journal of Trend in Scientific } \\
\text { Research and Development (IJTSRD) }\end{array}$ \\
\hline & UGC Approved International Open Access Journal \\
\hline & ISSN No: 2456 - 6470 | www.ijtsrd.com | Volume - 1 | Issue - 5 \\
\hline
\end{tabular}

\title{
Effect of Swift Heavy Ion Irradiation on Optical Properties of Poly Vinylidene Chloride (PVDC) Films
}

\author{
Kusam Devgan \\ Department of Physics, S. R. Government College for Women, \\ Amritsar, Punjab, India
}

\begin{abstract}
The lithium ion (50 MeV) having fluence range of $1 \times 1011$ ions $/ \mathrm{cm} 2$ to $3 \times 1012$ ions $/ \mathrm{cm} 2$ induced poly vinylidene chloride (PVDC) films have been examined using UV-Visible technique. The shift in optical absorption edge in irradiated PVDC was associated with the decrease in optical band gap energy. The noticeable characteristic peak was detected due to UV-Vis analysis, in lithium irradiated samples of PVDC at highest fluence.
\end{abstract}

Keywords: Polymer; Irradition; PVDC (Poly vinylidene chloride); SHI (Swift Heavy Ion); UV-VIS (Ultra violet-visible).

\section{INTRODUCTION}

Different studies of ion induced polymers revealed that the modifications occurred in properties of polymers are due to main chain scission, creation of carbonaceous clusters and formation of volatile fragments [1-4]. The reason behind this may be due to high electronic energy loss of swift heavy ions in the target [5].

Swift heavy ion irradiation of poly vinylidene chloride stimulated scission between the carbons of main chain and side substituent. This extended to cross linkages and creation of double bonds in main chain. The structural changes in PVDC irradiated with
$\mathrm{KeV}$ and $\mathrm{MeV}$ energies at several fluences and the photoluminescence phenomenon in PVDC due to irradiation with $84 \mathrm{MeV}$ Oxygen ions and $120 \mathrm{MeV}$ Silicon ions were described [6-7]. The ionic desorption from PVC and PVDC polymers induced by the photons reported to give strong selectivity in the formation of chlorine ions [8]. This paper is to explore the optical properties of PVDC films irradiated with lithium ions using UV-Vis technique.

\section{EXPERIMENTAL}

The specimens of Poly vinylidene chloride (PVDC) were procured from Good Fellow Ltd. (UK) in the form of flat polished thin films having thickness 50 $\square \mathrm{m}$. These films were used as-received form without any further treatment in the size of $1 \mathrm{~cm} \times 1 \mathrm{~cm}$. The samples were mounted on the sliding ladder and irradiated with lithium ( $50 \mathrm{MeV})$ ion beams using 15 UD pelletron facility in the general purpose scattering chamber (GPSC) under vacuum of $\sim 10-6$ Torr at Inter-University Accelerator Center, New Delhi, India. The ion beams fluence was varied from $1 \mathrm{x}$ 1011 to $3 \times 1012$ ions $\mathrm{cm}-2$. The range, electronic energy loss and nuclear energy loss due to irradiation with lithium $(50 \mathrm{MeV})$ ions in PVDC polymer are shown in table1 [9]. 


\section{Table 1: Electronic, Nuclear Energy Loss and Ion Range of polymer PVDC}

\begin{tabular}{|c|c|c|c|}
\hline Ion Beam & $\begin{array}{c}\text { Ion range } \\
(\boldsymbol{\mu m})\end{array}$ & $\begin{array}{c}\text { Electronic } \\
\text { Energy loss } \\
(\mathbf{e V} / \AA)\end{array}$ & $\begin{array}{c}\text { Nuclear } \\
\text { Energy loss } \\
(\mathbf{e V} / \AA)\end{array}$ \\
\hline Lithium (50MeV) & 475.57 & 6.627 & $3.304 \mathrm{E}-03$ \\
\hline
\end{tabular}

\begin{tabular}{|c|c|c|c|c|c|c|}
\hline $\begin{array}{l}\text { Ion Fluence } \\
\left(\text { ions } / \mathbf{c m}^{2}\right)\end{array}$ & Pristine & $1 \times 10^{11}$ & $3 \times 10^{11}$ & $6 \times 10^{11}$ & $1 \times 10^{12}$ & $3 \times 10^{12}$ \\
\hline$\frac{\text { Lithium }}{\frac{\text { (50MeV) }}{\text { (kGy) }}}$ & 0.00 & 6.51 & 19.54 & 39.08 & 65.13 & 195.44 \\
\hline
\end{tabular}

In order to expose the whole target area, the beam was scanned in the $\mathrm{x}-\mathrm{y}$ plane. The beam current was kept low, i.e. $\sim 0.5$ pnA (particle nanoampere), to suppress thermal decomposition and was monitored intermittently with a Faraday cup. Doses for the given fluence and ion type were calculated using the formula given in equation (1) and were provided in Table 2 [10].

$$
\text { Dose }=1.602 \times 10^{-10} \times \frac{1}{\rho} \times \frac{d E}{d x} \times \phi
$$

$\phi$ : Ion fluence, $\rho$ : Density of polymer, $\frac{d E}{d x}:$ Stopping power of ion

The samples were analyzed for UV-VIS spectroscopy using Lambda 35 Perkin Elmer UV-Vis spectrophotometer in the range 200-800 $\mathrm{nm}$ to observe the variation in optical band gap.

\section{RESULTS AND DISCUSSION}

Figure 1 showed the UV visible spectra of pristine and irradiated samples of Poly vinylidene chloride (PVDC). The spectra showed that there was a shift of absorption edge towards decreasing energy with the increase in ion fluence which may be due to the formation of unsaturated species due to irradiation with swift heavy ion.

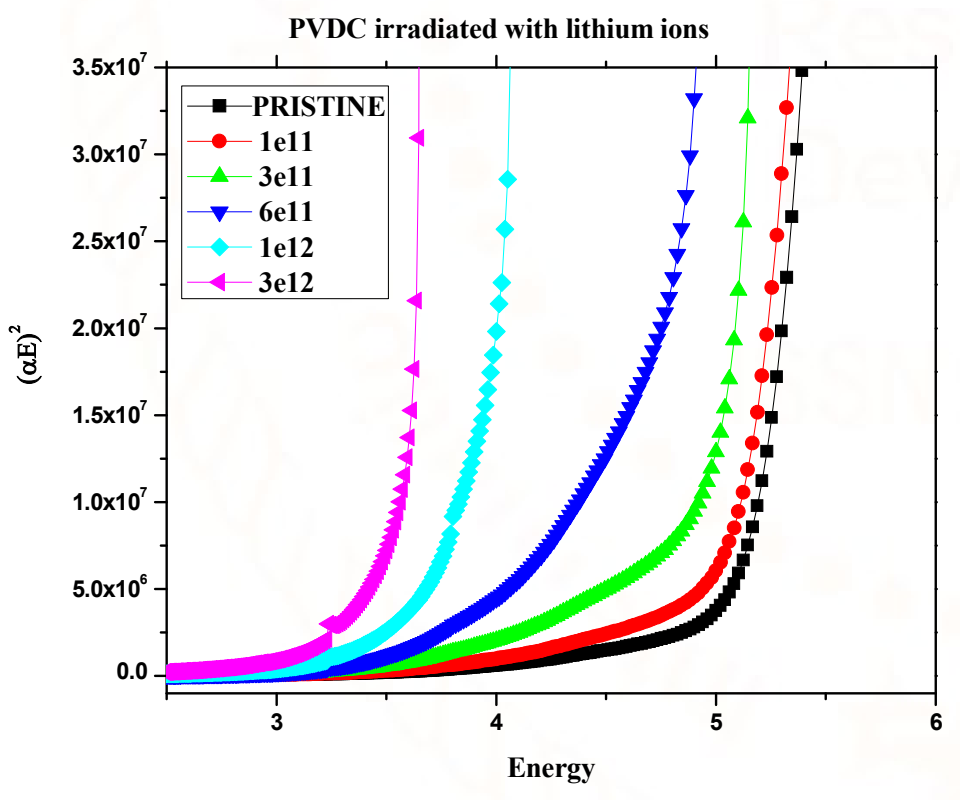

Figure 1: UV-Visible direct band spectra of PVDC irradiated with lithium ions at different fluencies

The noticeable characteristic peak was detected in lithium ion irradiated PVDC samples at highest fluence; this peak may be due to the electronic transition of non bonding electrons, occurring in the compounds containing fluorine, chlorine, nitrogen and oxygen etc [11]. 
The variation of $(\alpha h v) 2$ with photon energy hv for PVDC polymer was shown in Fig. 1.

$$
\alpha=\mathrm{B}(\mathrm{h} v-\mathrm{Eg}) / \mathrm{h} v
$$

$\alpha$ is absorption coefficient, hv is photon energy and Eg is value of optical band gap. These carbon enriched domains produced in polymer films during irradiation were accountable for the decrease in band gap [12-14].

\section{CONCLUSIONS}

The paper concludes that the swift heavy ion irradiation of PVDC films resulted to the shift of absorption edge towards decreasing energy with the increasing ion fluence.

\section{ACKNOWLEDGEMENTS}

IUAC (Inter-University Accelerator Center), New Delhi, is appreciatively acknowledged by the author for providing the swift heavy ion facility.

\section{REFERENCES}

1) D. Fink, W.H.Chung, R. Klett, A. Schmoldt, J. Cordoso, R. Montiel, M.H. Vazquez, L.Wang, F. Hosoi, H. Omichi and G.P. Langer Radiat. Eff. Def. Sol. 133 (1995) 193.

2) D. Fink, R. Klett, L.T. Chaddertron, J. Cardosa, R. Montiel, M.H. Vazquez and A.A. Karanovich Nucl. Instr. Meth.B 111(1996) 303.

3) L. Singh and K.S. Samra Radiat. Phys. Chem. 77 (2008) 252.

4) T. Steckenreiter, E. Balanzat, H. Fuess and C. Trautmann Nucl. Instr. Meth.B 131 (1997) 159.

5) E. Balanzat, A. Bouffard, S.A. Bouquerel, J. Devy and C. Gate Nucl. Instr. Meth.B 116 (1996) 159.

6) M.A. Parada, R.A. Minamisawa, C. Muntele, I. Muntele, A. de Almeida and D. Ila A I P Conf. Procced. 866 (2006) 304.

7) K.S. Samra, S. Thakur and L. Singh J. Lumin. $131(2011) 686$.

8) G.S. Faraudo, M.L.M. Rocco, F.C. Pontes, G.G.B. de Souza, R.R. Pinho and M. Ferreira Brazil. J. Phys. 36 (2006) 534.
9) J.F. Ziegler and J.P. Biersack SRIM-(2008) IBM Research, New York.

10) O.B. Gei $\beta$, M. Kramer and G. Kraft Nucl. Instr. Meth.B 142 (1998) 592.

11) A.K. Srivastava and H.S. Virk Bull. Mater.Sci. 23 (2000) 533.

12) D. Fink and W.H. Chung Nucl. Instr. Meth.B 168 (2000) 59.

13) H.S. Virk, P.S. Chandi and A.K. Srivastava Nucl. Instr. Meth.B 183 (2001) 329.

14) T. Phunkan, D. Kanjilal, T.D. Goswami and H.L. Das Radiat. Meas. 36 (2003) 611. 